\title{
Demography and electrical energy in the economy of large Cameroonian cities
}

\author{
Abdoulay Mfewou ${ }^{1}$; Youssouf Monkouop ${ }^{2}$; Francis Merlin NZogne ${ }^{3}$ \\ ${ }^{1}$ Lecturer-Researcher, University of Dschang-Cameroon \\ ${ }^{2}$ Researcher. University of Dschang-Cameroun \\ ${ }^{3}$ Researcher. University of Dschang-Cameroun \\ Corresponding author; Abdoulay Mfewou
}

Received: 18, July, 2021

Accepted: 26, July, 2021

Published:31July 2021

\begin{abstract}
This article shows that Cameroon remains the second hydroelectric potential of Africa after the Democratic Republic of Congo. Started in the 1950s and developed in 2001 by the national policy, strategy and action plan for energy efficiency in the electricity sector in Cameroon with the construction of hydroelectric dams and thermal power plants, the result of this policy Slow is the persistence of difficulties in supplying electrical energy, which leads to continuous load shedding on the one hand, and the limits linked to supplies in a context of increasing urbanization (2.5\%) on the other. Although the correlation between population growth and energy consumption remains present for economic growth in cities, the rate of GDP is $5.77 \%$ and remains constant among other things, from the energy crisis in all cities of the country.
\end{abstract}

Keywords: demography, economics, electrical energy, urban.

\section{Introduction}

In the context of energy emergence (Jaglin, S. and Verdeil, E., 2013; Duruisseau, K., 2014); the economic sector of Cameroonian cities is characterized by a strong acceleration in the growth of urban consumption capacities, household savings, investment in small and medium-sized enterprises in the private sector, this dynamic reinforcing the attractiveness in favor of cities from the rural population. We are witnessing a national economic boom of $4.7 \%$ accompanied by population growth of only $2.6 \%$. The production of manufacturing goods and services increases while social inequalities remain high. Thus, the increase in the number of households increases residential energy demand while little new energy supply is observed. This potentially difficult situation can be explained by a combination of political, economic and technological choices, in particular regarding the construction of hydroelectric dams in the country.

\section{Urban growth and low energy supply}

Cameroon has significant potential for energy sources (see map). This energy is used directly to produce light or heat for both urban and rural consumption. The country uses several forms of energy: flux energies (electric energy), stock energies (chemical energy) as well as renewable energies. The energy sector is however characterized by an insufficient supply on a national scale in spite of significant potentials as regards hydroelectric energy, the various renewable energies (solar, biomass) and even the deposits of natural gas ( Modeste Nkutchet, 2004; Yris D. Fondja Wandji, 2007). Oil has also been exploited in Cameroon since the early 1980s. Primary energy production was split in 2014 between biomass for $50 \%$ of total production, hydroelectricity for $4.5 \%$ and fossil fuels for $45.3 \%$, including oil at $39.6 \%$ and natural gas at $5.7 \%$. Also, imports and exports of primary energy consumed in the country in 2014 were divided into $64.4 \%$ for biomass, $5.7 \%$ for hydroelectricity and $30 \%$ for fossil fuels (petroleum products $22.5 \%$ and gas $5.3 \%$ ). Electricity production was divided in $73 \%$ of hydroelectricity, $1 \%$ of biomass and $26 \%$ of fossil fuels in 2014 (petroleum 12.8\% and natural gas 12.9\%).
The energy supply, produced in the country or imported, does not make it possible to face the constant increase in the demand for electricity because of this growth of the urban and rural population and the economic development associated with the modernization of technological equipment. (Pompidou Folefac D., Sale A., 2009). The regular load shedding linked to this situation, leaving the population in continuous darkness, indicates the gravity of the energy crisis which the country is going through and which has harmful impacts on the national economy, the quality of work and the living conditions of populations, while population growth, economic growth and increased energy supply are inseparable realities to support the development of a nation.

In this situation can we speak of the achievement of the country's emergence objectives, announced in the strategic political speech "Emergence in 2035". ? Is there a relationship between the growth of urban economic activity and the consumption of electrical energy in large Cameroonian cities? To answer these questions, our approach is based on the analysis of the country's energy archives and the literature relating to this theme, then on the lessons learned and analyzed by a series of interviews with stakeholders. The goal is ultimately to build a reflection on the energy policy projects in progress.

The construction of the Lom Pangar hydroelectric dam 13 kilometers upstream from the confluence with the Sanaga, the commissioning of which was planned for late July 2016, is still low and should help increase the production capacity of Song Loulou power plants by $120 \mathrm{MW}$ and Edea. According to the African Development Bank, this project increases the guaranteed power of the two plants from $450 \mathrm{MW}$ to $729 \mathrm{MW}$; in addition, a $30 \mathrm{MW}$ hydroelectric power station is built at the foot of the dam and connected to the Bertoua thermal plant by a $105 \mathrm{~km}$ line in $90 \mathrm{KV}$, which extends over $200 \mathrm{~km}$ to the localities of Batouri and AbongMbang, in order to make the performance of the transport and distribution systems more reliable and to extend the supply of energy to 150 localities in the Eastern region. The impoundment of the dam was almost finished at the end of October 2016, with 5 billion cubic meters out of the 6 planned. Other reservoir dams, of smaller size, were built previously in the 1970s and 1980s in order to regulate the flow of the Sanaga and to partially overcome the low water problems: the Mbakaou dam, with a capacity of 2.6 
billion $\mathrm{m}^{3}$ in the Adamawa region, that of Mapé (3.2 billion $\mathrm{m}^{3}$ ) and that of Bamendjing ( 1.8 billion $\mathrm{m}^{3}$ ) in West Cameroon.

Even today, barely $70 \%$ of the population has access to continuous electricity, despite the privatization in July 2001 of the public electricity service which is supposed to improve this painful situation. While this forced reform was perceived by the cantors of liberalism at all costs as a panacea, the energy crisis persists and it has disastrous consequences on both economic and social levels by regular national power cuts.

Many other slow projects are planned on the Sanaga river, the potential of which exceeds 3,000 MW: the Nachtigal-upstream hydroelectric dam project (420 MW, commissioning scheduled for 2021); Song Mbengue dam project (950 MW) $15 \mathrm{~km}$ upstream of the current Song Loulou hydroelectric dam; Song Dong project (300 MW), downstream from Lom Pangar; Kikot project (630 MW); Grand Eweng project (1,200 MW).

The hydroelectric results show that there is a correlation between population growth and energy consumption for economic growth in Cameroonian cities, with a negative effect on the biodiversity that we recorded during the construction of dams (Lagdo, Mbakaou, Lom Pangar ...), With the disappearance of ecosystems (during the impoundment of dams) including natural reserves and the relocation of habitats on the one hand, there was also the disturbance of water flows upstream and downstream of the installations hydroelectric, the disturbance of the migratory routes of certain fish species on the other hand on an ecological level.

\section{Demography, electrical energy and evolution of the real rate of GDP}

With a birth rate of $31.93 \%$ (2013), of a population of 23,248,044 inhabitants (2017); of energy consumption, the Cameroonian economy has experienced an irregular development with a low level of activity, characterized by a growth rate of $8.06 \%$ in 1985 then this GDP remains decreasing and steady in 2017, the causes of which are both internal and external, we note the fall in commodity prices, implementation of Structural Adjustment Programs (SAP).

Effects of the 2001 and continuous electric energy crisis on manufacturing production, trade, and the drop in rainfall in different regions of the country on agricultural production, thus by regular load shedding penalize businesses and services (Figure 1;2 and 3)

The Cameroonian manufacturing industry is more diversified than that of neighboring countries. In 2005, it represented around $18.9 \%$ of total GDP. In addition, the overall growth rate of this sector increased, going from $4.7 \%$ in 2005 to $5.1 \%$ in 2006 . However, performances were mixed according to the fields. Thus, in the Littoral region: port city, the large energy consumption by the company ALUCAM gives an aluminum production of $6,2 \%$ in progression to reach 92,000 tons, thanks to the international prices, which are maintained at a high level.

In the agro-food sector, which suffered the full impact of the $4 \%$ drop in household consumption in 2005, the estimated increase in production was $3.5 \%$ in 2006 . The beverage sector, in on the other hand, recorded a $9 \%$ drop in production in 2006, after a drop of $12.5 \%$ already noted in 2005 . The growth of the manufacturing sector, although relatively vigorous in 2006, remains hampered by a number of structural difficulties. Among the main problems is the inadequacy of energy supply across the country. The current power production of the Cameroon Sugar Company (Sosucam) is 49.68 GWh, and is expected to reach approximately $73 \mathrm{GWh}$ in 2017.

Electricity remains expensive $(70 \mathrm{Fcfa} / \mathrm{Kwh})$ and power cuts are very frequent, which shows the difficulties encountered by households and services. Indeed, the hydrological resources of the country are the most important of sub-Saharan Africa (after those of the Democratic Republic of Congo), but only $1 \%$ of this wealth is exploited. Hydroelectricity accounts for approximately $77 \%$ of the installed capacity, which stands at 933 megawatts. But the recent drop in water levels in major dams, as well as the poor condition of power plants and transportation equipment, have cut that production capacity by about a third. As a result, electricity supply remains far below demand, currently estimated at 1,000 megawatts (AfDB / OECD 2007).

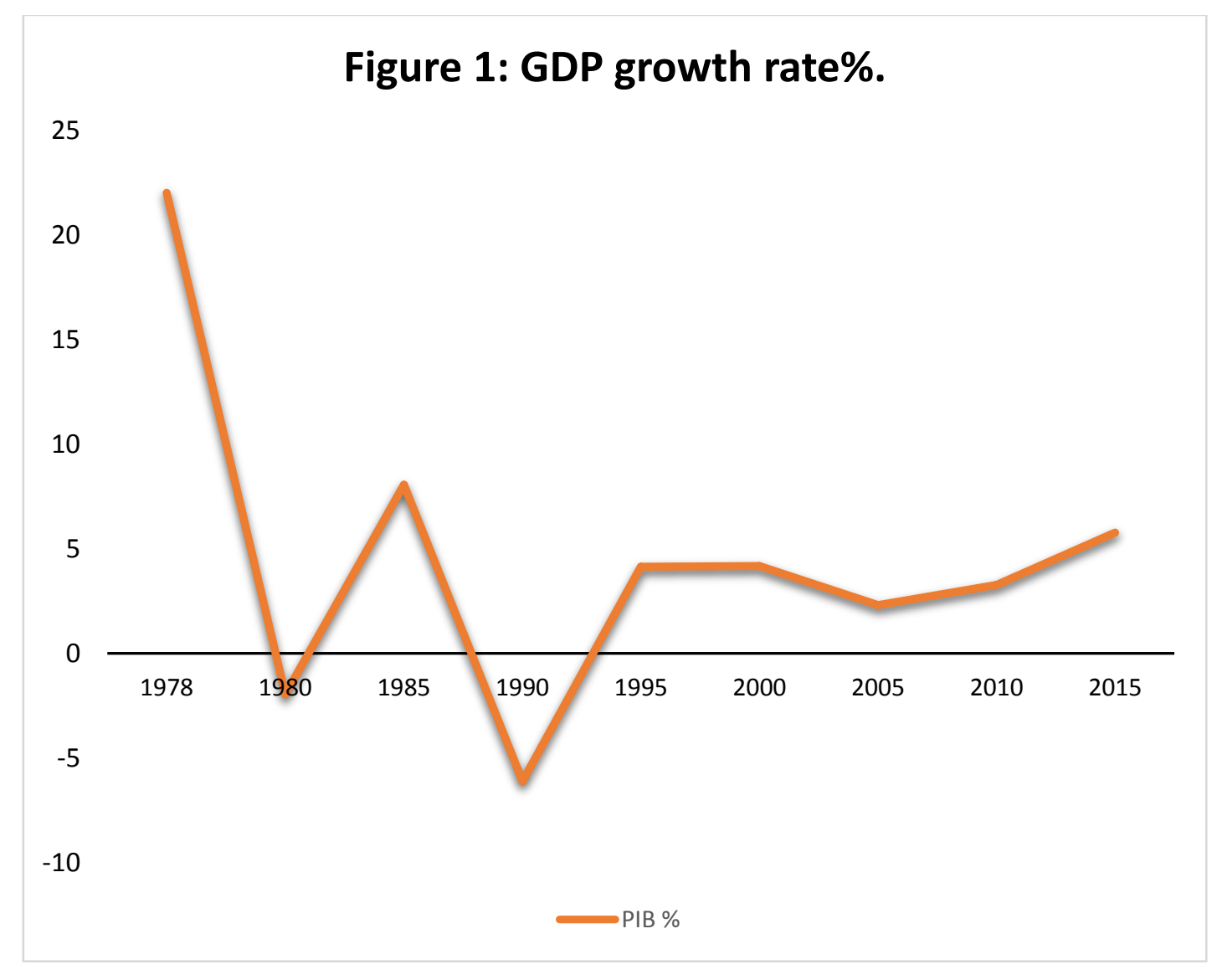




\section{Figure 2: Population growth rate (\%)}

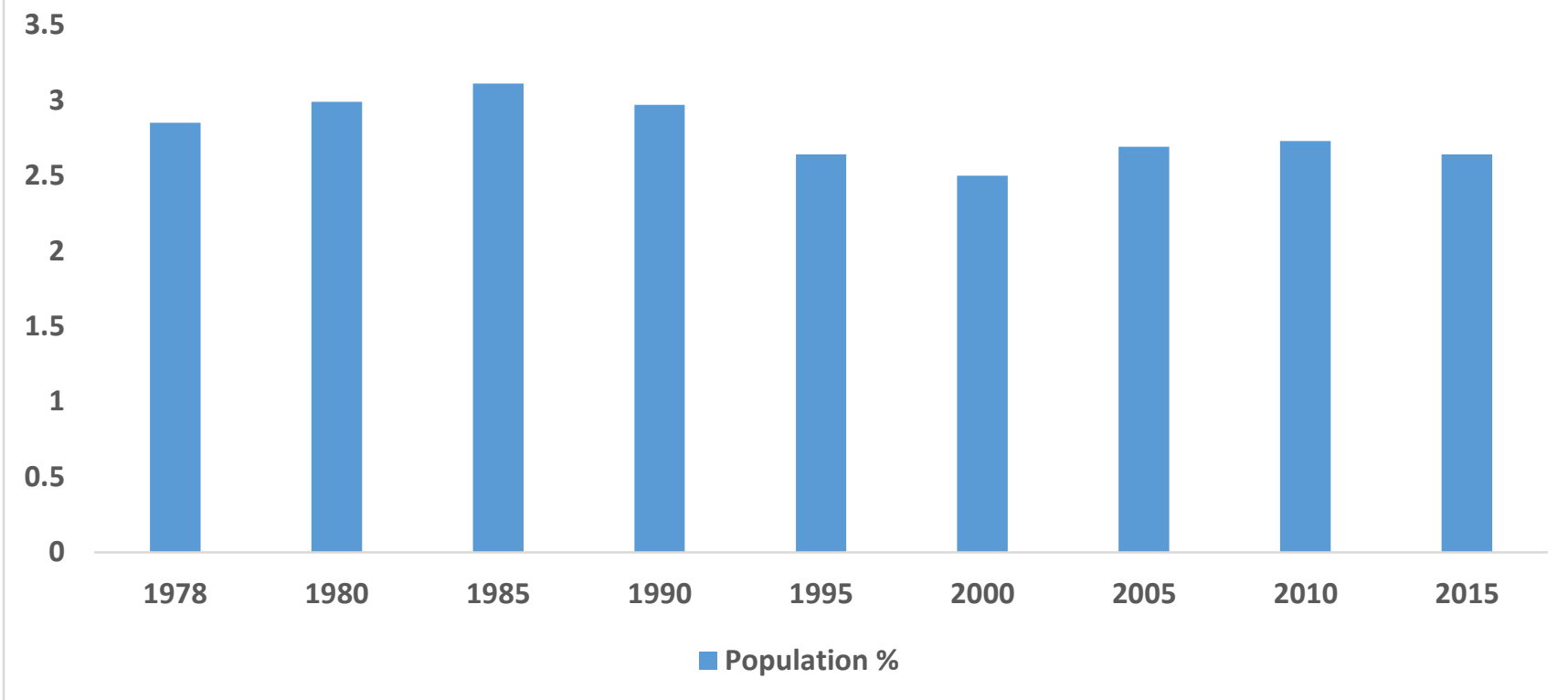

These figures show that the population growth rate is increasing and the GDP growth rates have increased from $22 \%,-1.97 \%, 8.06 \%,-6.11 \%$, $4.17 \%, 5$ respectively. , 77\% in 1978, 1980, 1990, 1995, 2000, and 2015, But, in 1995, the GDP growth rate fell by $-6.11 \%$ due, among other things, to the energy crisis in the all the cities of the country.

In the energy policy, the installed and exploited power is estimated at around $1060 \mathrm{MW}$, mainly distributed between the hydroelectric and thermal sources which constitute the public electricity network. There are also some self-production units that do not depend on the public grid (generator, solar panel, etc.). The great part of electricity is supplied first to industries and then in agglomerations which remain in full expansion in cities and peri-urban areas.

Figure 3: Energy according to the sources of production in MW (dam)

450

400

350

300
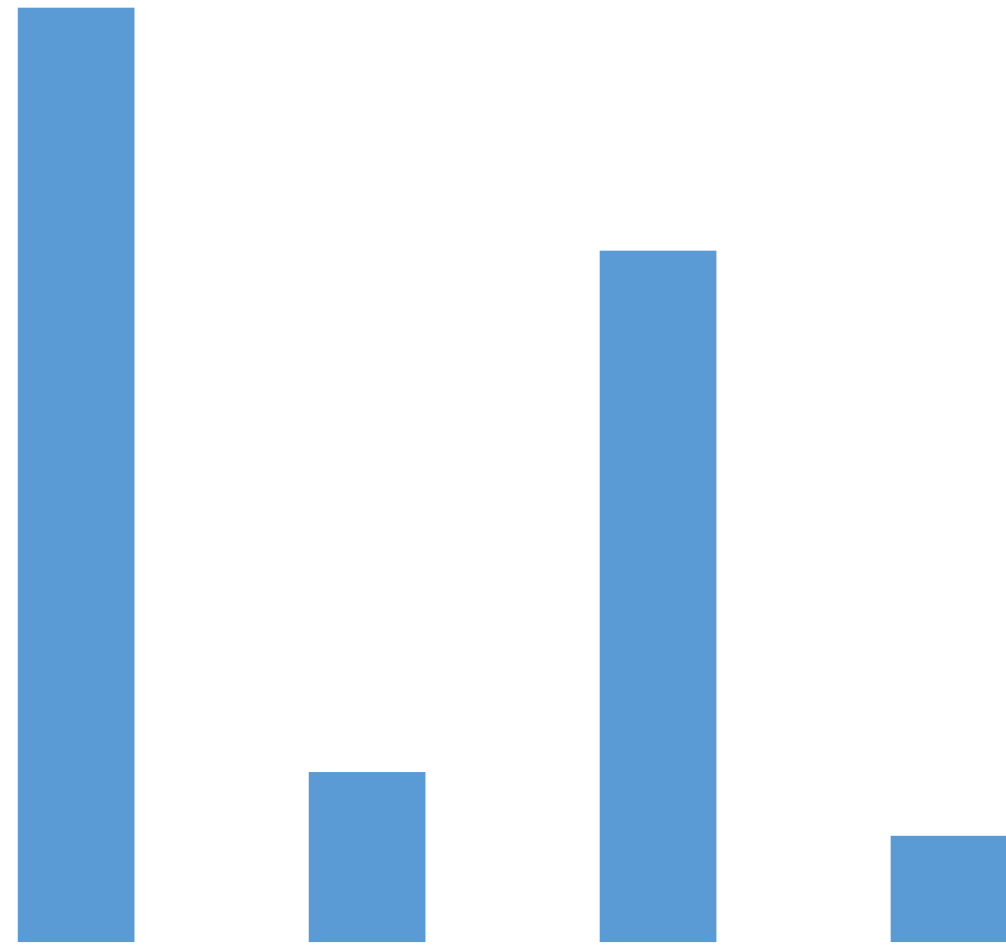

Edéa

Songlulu

Lagdo

Thermique

Autres 

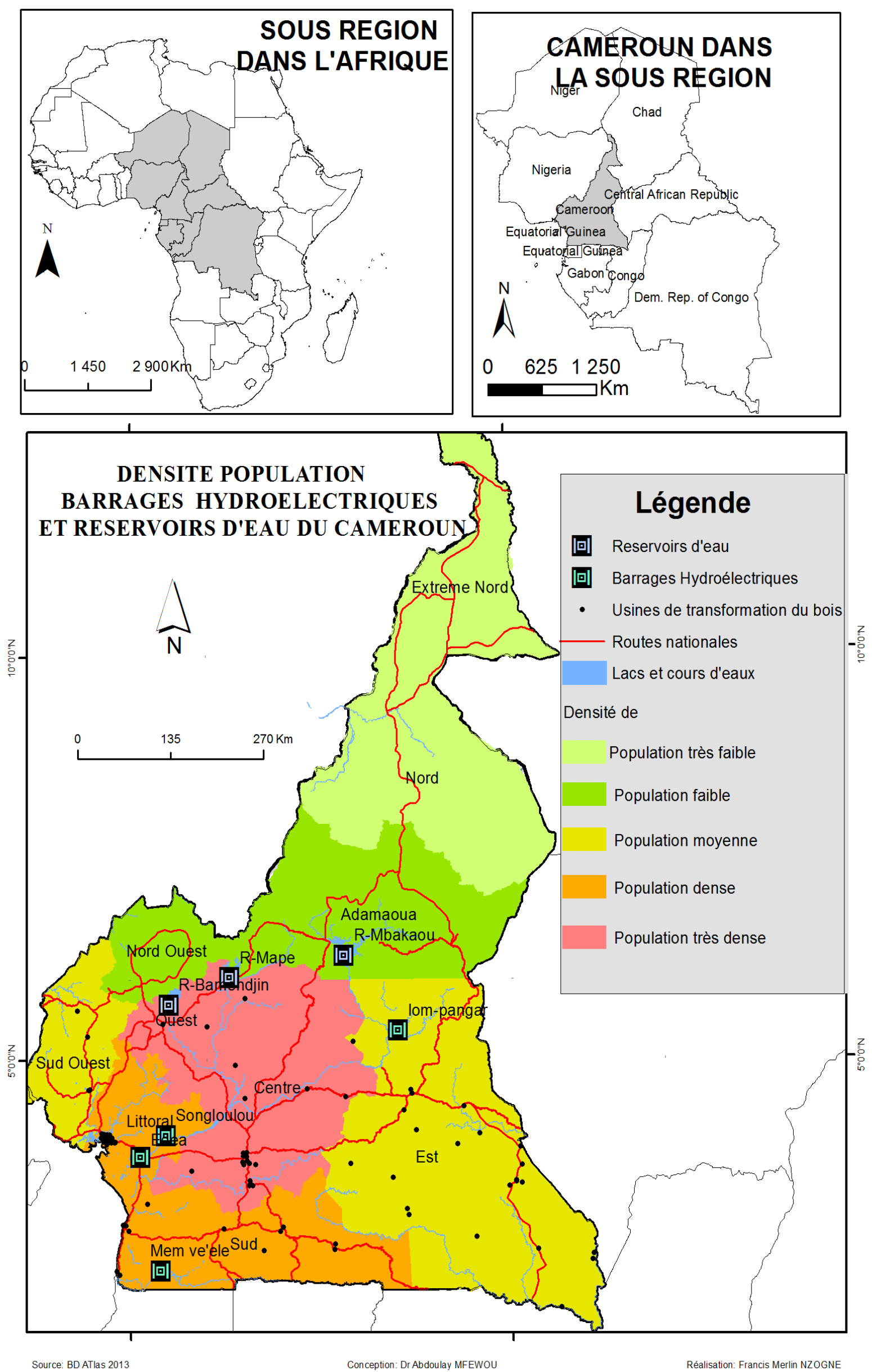


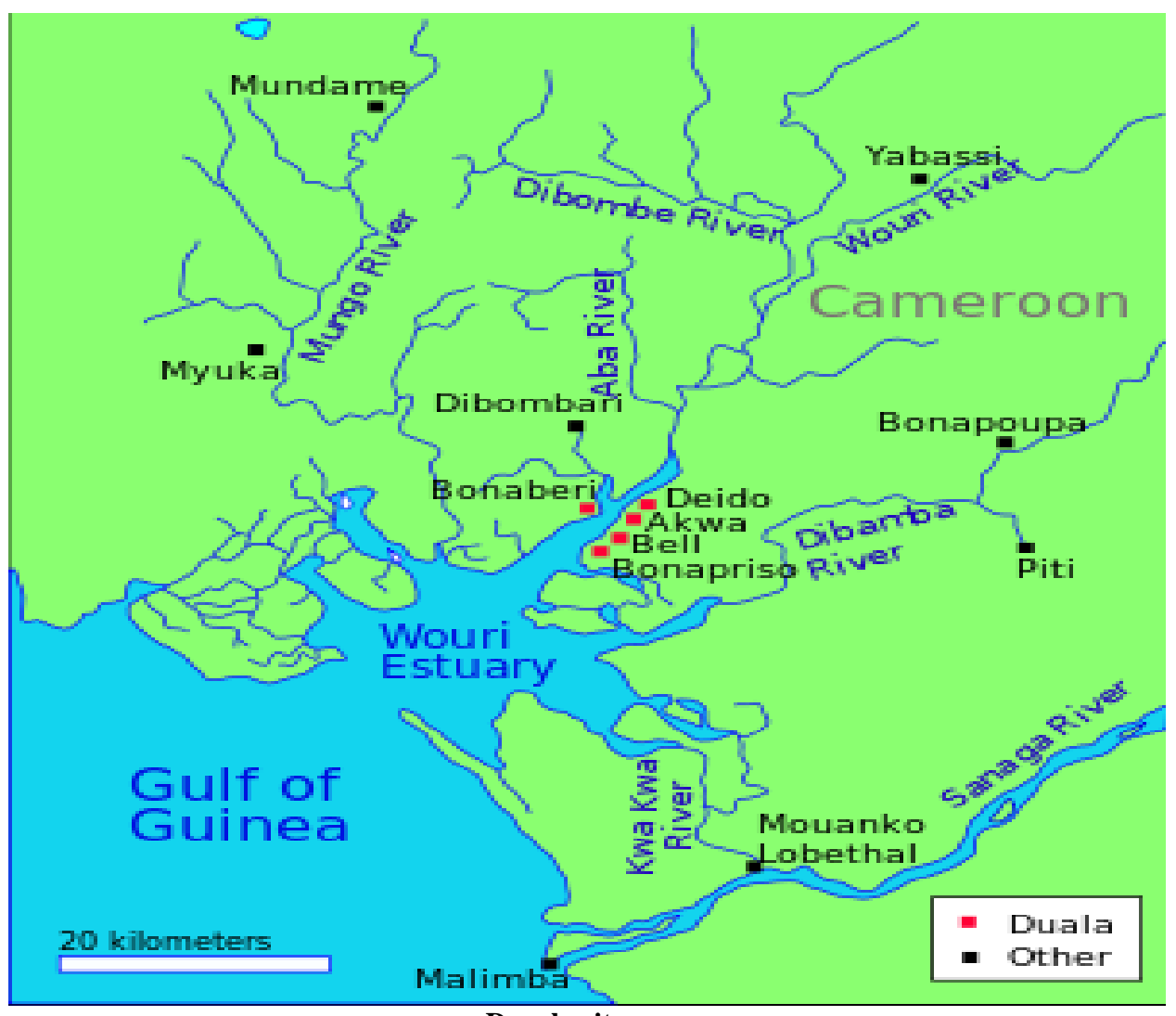

Douala city map

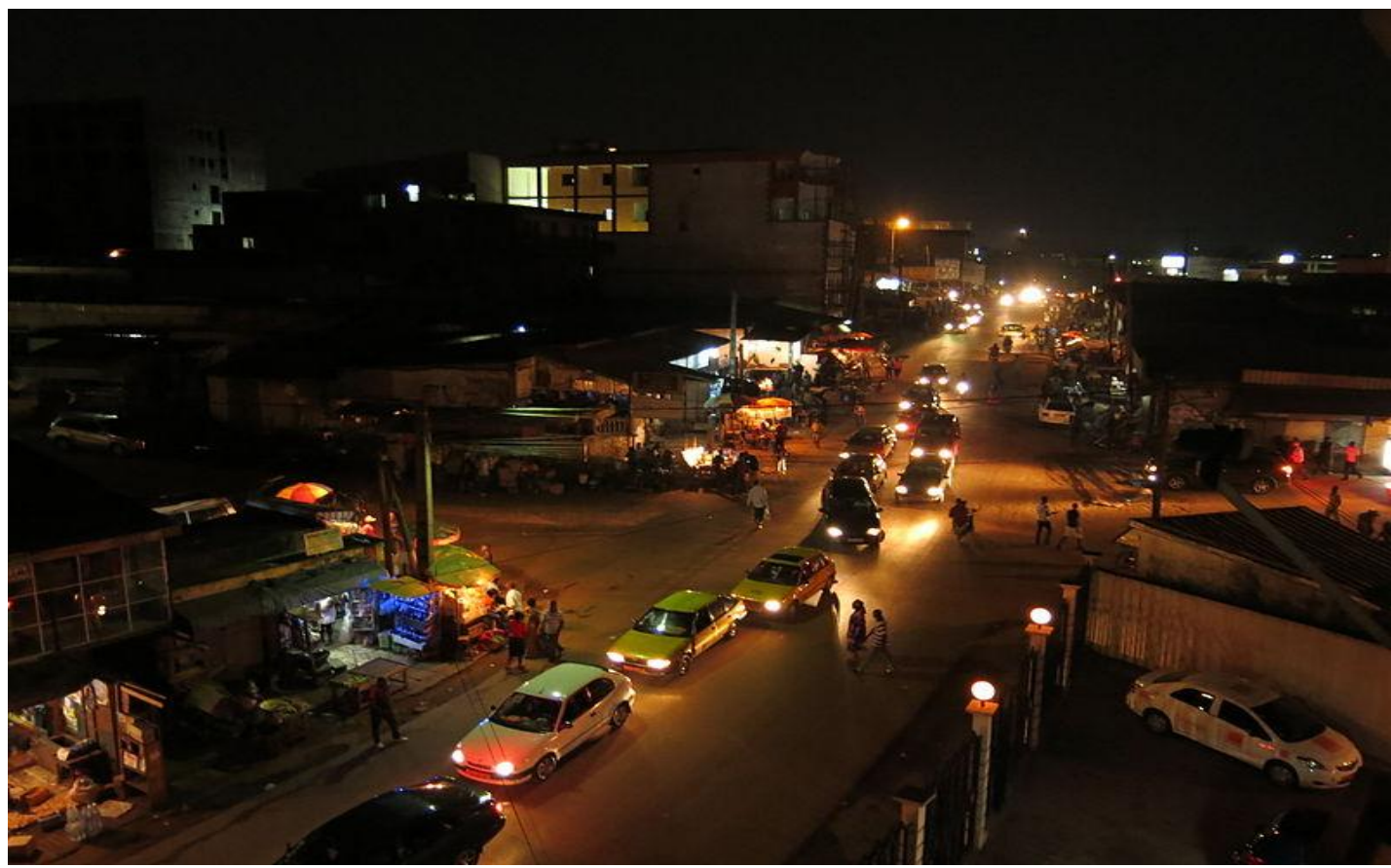

The town of Yaoundé at night

\section{Conclusion}

With a galloping demography, the study shows that, sixteen years after the privatization of the energy sector in Cameroon, the situation has hardly changed the supply of energy remains far below demand. The passage of POWERCAM by SONEL 2001, July 17, date of Privatization of SONEL for the benefit of AESSirocco Limited, a subsidiary of AES Corporation, this is the era of AES-SONEL at ACTIS and on 12 September 2014: The new company name is announced. It is the Eneo Cameroon SA (Eneo) era. In this historical evolution the population increases and the load shedding persists and the need for electrical energy also increases to cover 25 million Cameroonians and for the functioning of the different industries installed in the regions.

The change in status of the electricity supplier has had no proven impact on the economy of consumers, on the contrary. We always deplore as many electrical inconveniences characterized by frequent and untimely load shedding. All categories of companies are badly affected. In this difficult energy production, the highly agricultural rural area less covered by the electricity network, registers a strong disparity between urban areas which remains more or less with overloads of electric cables on less secure poles.

Another factor, not least of which is developing electrification in Cameroon, is its price, which remains too high (70Fcfa / Kw). With low production, the excessive increase in tariffs, fees or taxes imposed on businesses and the population penalizes this population 
(drop in consumption) and the competitiveness of these businesses (increase in production costs).

These energy crises are manifested by load shedding of increasingly long duration. They have negative impacts on the national economy. They jeopardize economic growth (GDP), the improvement of living conditions and the quality of work of the populations, and even the achievement of the country's emergence objectives, described in the strategic document "Cameroon will emerge in 2035".

The country must demonstrate very great capacity to adapt to this situation, which remains a social, economic and environmental concern.

\section{References}

[1] Duruisseau, K. (2014). The emergence of the concept of energy transition. What contributions from geography $B S G L g$.

[2] Folefack, D. P., \& Abou, S. (2009). Marketing of firewood in the Sahelian zone of Cameroon. Science and planetary change / Sécheresse,, 20(3), 312-318.

[3] Jaglin, S., \& Verdeil, E. (2013). Energy and cities in emerging countries: transitions in question. Introduction. Flux, (3), 7-18.

[4] Wandji, F., \& Dieunedort, Y. (2011). Which sustainable energy strategies for developing countries: the case of the electricity sector in Cameroon (Doctoral dissertation, Paris 9).

[5] Gondie, H., \& Messi, B. P. E. (2016). Urban sprawl and spatial disparity in modes of access to electrical energy in the city of Ngaoundéré (North-Cameroon). International Journal of Humanities and Cultural Studies (IJHCS) ISSN 2356-5926, 2(3), 342-353.

[6] Greggio, R., \& Mafféi, B. (2016). Energy shortage, insurmountable obstacle to economic growth in African countries?. Géoéconomy, (5), 133-148.

[7] Jaglin, S., \& Verdeil, E. (2013). Energy and cities in emerging countries: transitions in question. Introduction. Flux, (3), 7-18.

[8] Modeste Nkutchet, (2004) Energy in Cameroon, L'Harmattan, 2004, 440 p. (ISBN 9782296377882)

[9] Yris D. Fondja Wandji, (2007) Cameroon and the energy question: analysis, assessment and perspectives, Editions L'Harmattan, 2007, 141 p. (ISBN 9782296024939 et 2296024939 ).

[10] Denis Pompidou Folefac et Sale Abou (2009), "Marketing of firewood in the Sahelian zone of Cameroon", Sécheresse, 2009. 